\title{
Should Research Ethics Encourage the Production of Cost-Effective Interventions?
}

\author{
Govind Persad
}

\begin{abstract}
This project considers whether and how research ethics can contribute to the provision of cost-effective medical interventions. Clinical research ethics represents an underexplored context for the promotion of cost-effectiveness. In particular, although scholars have recently argued that research on less-expensive, lesseffective interventions can be ethical, there has been little or no discussion of whether ethical considerations justify curtailing research on more expensive, more effective interventions. Yet considering cost-effectiveness at the research stage can help ensure that scarce resources such as tissue samples or limited subject populations are employed where they do the most good; can support parallel efforts by providers and insurers to promote cost-effectiveness; and can ensure that research has social value and benefits subjects. I discuss and rebut potential objections to the consideration of cost-effectiveness in research, including the difficulty of predicting effectiveness and cost at the research stage, concerns about limitations in cost-effectiveness analysis, and worries about overly limiting researchers' freedom. I then consider the advantages and disadvantages of having certain participants in the research enterprise, including IRBs, advisory committees, sponsors, investigators, and subjects, consider cost-effectiveness. The project concludes by qualifiedly endorsing the consideration of cost-effectiveness at the research stage. While incorporating cost-effectiveness considerations into the ethical evaluation of human subjects research will not on its own ensure that the health care system realizes cost-effectiveness goals, doing so nonetheless represents an important part of a broader effort to control rising medical costs.
\end{abstract}

\section{Introduction}

The moral importance of cost-effectiveness has gained prominence in recent debates about funding medical care. Toby Ord at Oxford, for instance, has argued 
that there is a moral imperative to use public funding to provide the most costeffective interventions, such as preventive care for blindness-causing infections like trachoma, rather than more expensive and less cost-effective interventions such as guide dogs (Ord 2013). Recent debates over the cost-effectiveness of programs like the President's Emergency Plan for AIDS Relief (PEPFAR) raise similar issues (Denny and Emanuel 2008; Emanuel 2012a).

This project considers whether researching cost-effective interventions is morally desirable, in contrast to the above arguments, which aim to establish the ethical importance of providing cost-effective interventions. The view that research must have social value in order to be ethical has been prominently defended (Emanuel et al. 2000). If social value depends to some extent on costeffectiveness, as many believe, then the cost-effectiveness of the intervention being studied will affect whether research into that intervention is ethical. Research will then serve as an institutional gatekeeper in the service of cost-effectiveness, just as many have argued that governments, insurers, physicians, and patients should work to promote interventions that are cost-effective over those that are not.

I argue for a stance of cautious optimism toward proposals that we consider cost-effectiveness when evaluating the ethics of proposed research interventions. But I believe that using research ethics to focus research on interventions that are cost-effective faces several challenges, most importantly that (1) enforcing costeffectiveness norms and (2) predicting either effectiveness or cost are particularly difficult at the research stage. Notwithstanding these challenges, research ethics constitute an underexplored and potentially important part of the enterprise of promoting cost-effectiveness in medicine.

\section{Cost-Effectiveness in the Development of New Interventions}

Cost-effectiveness analysis in medicine involves comparing the cost of medical interventions, such as pharmaceuticals or devices, against the effectiveness of these interventions at producing a desired health outcome. Policymakers and medical ethicists have argued that medicine should place a greater emphasis on promoting the use of interventions that are cost-effective and discouraging the use of those that are not (Emanuel and Fuchs 2008; Orszag and Ellis 2007; Mortimer and Peacock 2012). In circumstances of scarcity, some argue that cost-effectiveness rises to the level of a moral imperative: spending a limited pool of money on interventions that are cost-effective enables us to meet more health needs (Denny and Emanuel 2008; Ord 2013).

The provision of medical interventions to patients represents the culmination of a multi-stage process involving many actors, and providing many avenues for policy initiatives to promote cost-effectiveness. Consider, for example, the development of lovastatin, the first of the widely prescribed cholesterol-lowering "statin" drugs. During the 1970s, basic science research uncovered the biosynthetic path- 
ways by which humans synthesize cholesterol and discovered that compounds such as lovastatin inhibit that pathway in fungal models and in preclinical research on animals; during the 1980s, lovastatin entered clinical trials; and in 1987, lovastatin was approved by the FDA in the United States (Tobert 2003). Lovastatin was quickly accepted by physicians and patients, although some hospitals and insurers attempted to restrict its use as a first-line treatment due to its high cost at the time (Grabowski 1998; Lederle and Rogers 1990). The story of lovastatin illustrates the pathway from the discovery of a promising compound to the provision of a medical intervention. Although cost-effectiveness considerations only entered the process at the hospital or insurer stage in the case of lovastatin, cost-effectiveness considerations can and do enter at upstream and downstream stages as well (Table 1). Downstream, value-based insurance designs could encourage patients to choose cost-effective interventions (Thomson et al. 2013). Codes of ethics could encourage physicians to provide cost-effective interventions (Emanuel 2012b; Weinberger 2011). Upstream, governmental bodies could provide costeffectiveness information to insurers, hospitals, and physicians (Wilensky 2006). Regulatory agencies could consider an intervention's cost-effectiveness when deciding whether to approve it for marketing (Paltiel and Pollack 2010). And-as this chapter discusses-investigators, sponsors, research ethics committees, and research participants could consider an intervention's cost-effectiveness when deciding whether to begin a clinical trial.

Table 1 Promoting Cost-Effectiveness in the Development of New Interventions

\begin{tabular}{|c|c|c|}
\hline Stage & Actors & Strategies to Promote Cost-Effectiveness \\
\hline $\begin{array}{l}\text { Basic science re- } \\
\text { search }\end{array}$ & $\begin{array}{l}\text { Scientists } \\
\text { Sponsors }\end{array}$ & Prioritize funding for cost-effective interventions \\
\hline $\begin{array}{l}\text { Preclinical and clini- } \\
\text { cal trials }\end{array}$ & $\begin{array}{l}\text { Investigators } \\
\text { Sponsors } \\
\text { Research subjects } \\
\text { Research ethics com- } \\
\text { mittees }\end{array}$ & $\begin{array}{l}\text { Prioritize funding for cost-effective interventions } \\
\text { Consider cost-effectiveness when approving trials } \\
\text { Choose not to pursue research on cost-ineffective } \\
\text { interventions } \\
\text { Refuse to participate in trials of interventions that } \\
\text { are not cost-effective }\end{array}$ \\
\hline $\begin{array}{l}\text { Approval for market- } \\
\text { ing }\end{array}$ & $\begin{array}{l}\text { Regulatory agency (e.g. } \\
\text { FDA) }\end{array}$ & Consider cost-effectiveness in approval process \\
\hline $\begin{array}{l}\text { Approval for reim- } \\
\text { bursement }\end{array}$ & $\begin{array}{l}\text { Insurers (e.g. Blue } \\
\text { Cross, Medicare) }\end{array}$ & $\begin{array}{l}\text { Reimburse based on cost-effectiveness } \\
\text { Tax insurance that provides cost-ineffective inter- } \\
\text { ventions }\end{array}$ \\
\hline $\begin{array}{l}\text { Use in clinical prac- } \\
\text { tice }\end{array}$ & Hospitals, physicians & Use formularies \\
\hline $\begin{array}{l}\text { Use with specific pa- } \\
\text { tients }\end{array}$ & Physicians, patients & $\begin{array}{l}\text { Educate physicians about cost-effective practice } \\
\text { Adopt value-based insurance that incentivizes pa- } \\
\text { tients to choose cost-effective interventions }\end{array}$ \\
\hline
\end{tabular}




\section{Why Promote Cost-Effective Interventions at the Research Stage?}

Cost-effectiveness considerations are not altogether foreign to debates over which interventions should advance to human testing. However, the most active debates about the relevance of cost-effectiveness to human-subject research focus on whether cost-effectiveness considerations can expand, rather than limit, the scope of allowable research. These debates arise in response to proposed research on "less expensive, less effective" interventions: those that promise to be more costeffective than the status quo, at some sacrifice to absolute effectiveness. Examples include research on less costly methods of lead abatement (Buchanan and Miller 2006), less costly treatment for multiple sclerosis (Lie 2004), replacement of multidrug regimens by monotherapy for HIV (Girardi and Angeletti 2013), and less costly prevention of maternal-fetal HIV transmission (Wendler et al. 2004).

That an intervention's cost-effectiveness can make research that would otherwise be disallowed ethical, as many of the above authors argue, suggests that costeffectiveness has moral significance in the research context. This paper explores the heretofore ignored "flip side" of the debate above: whether an intervention's lack of cost-effectiveness can render research into that intervention ethically objectionable.

Dividing interventions into the four quadrants of the cost-effectiveness plane (Black 1990) helps to illustrate the relationship between the "less expensive, less effective" debate and the questions explored in this paper:

Table 2 Research Ethics and the Cost-Effectiveness Plane

\begin{tabular}{|l|l|l|}
\hline & More Cost-Effective & Less Cost-Effective \\
\hline More Absolutely Effective & Consensus permission to research & $\begin{array}{l}\text { Consensus permission to re- } \\
\text { search, challenged here }\end{array}$ \\
\hline Less Absolutely Effective & Research permissibility debated & $\begin{array}{l}\text { Consensus prohibition on re- } \\
\text { search }\end{array}$ \\
\hline
\end{tabular}

Research on "dominant" interventions, those promising to be both more costeffective and more effective than the status quo, seems clearly acceptable. Research on "dominated" interventions, those less cost-effective and less absolutely effective than the status quo, seems clearly unacceptable. The question I explore here is whether we can treat research in the northeast quadrant as unproblematic while strenuously debating research in the southwest quadrant. Other commentators have argued for more parallel treatment of the two quadrants at the stage of reimbursement and prescribing decisions (Dowie 2004) but this debate has not so far extended to research. 
The numerous policy proposals discussed in Part I-from physician education to value-based insurance to cost-effectiveness thresholds for reimbursement-all restrict the provision of interventions that are not cost-effective, even though they may be absolutely effective. In contrast, the current consensus in research ethics seems to treat research into interventions that are more absolutely effective but less cost-effective as ethically unproblematic. Yet considering cost-effectiveness in research could improve the use of scarce resources, reduce pressure on actors at downstream stages, and ensure that research risks to subjects are appropriately counterbalanced by social benefits.

\subsection{Appropriate Use of Scarce Resources}

First, clinical research-like the provision of interventions-occurs within a broader context of scarcity. Some research requires the use of scarce medical resources such as fetal tissue (Woods and Taylor 2008). Other research, such as research on pediatric mood disorders, can only be performed on a limited population of subjects, which makes subjects a scarce resource (Frank et al. 2002). Some have argued that research subjects are a scarce resource in general (London et al. 2013; Dresser 2012). Where scarcity exists, priorities must be set, and costeffectiveness considerations can help us use limited research resources to produce interventions that will help more patients.

\subsection{Supporting Downstream Actors}

Second, it may be easier to restrict the provision of treatment on cost-effectiveness grounds at earlier stages, such as research or approval, than at later stages, such as the physician-patient interaction (Garber 1994). First, those who have invested time and money in researching the intervention will have a stake in lobbying against cost-effectiveness restrictions, as pharmaceutical manufacturers did after the Australian national health insurance agency declined to cover a cervical cancer vaccine (Roughead et al. 2008). Second, the further the intervention progresses, the more likely it becomes that physicians and patients will come to expect or aspire to receive the new intervention; if they treat these expectations or aspirations as their new baseline, they will frame the denial of reimbursement as a psychologically more upsetting loss rather than a mere failure to gain. For instance, it is difficult to cease provision of a drug that was being provisionally provided while its effectiveness was assessed, even if the drug proves ineffective. (While restrictions on basic science also have these attractions, the multi-purpose nature of basic science means that it will be harder to target restrictions without interfering with research that may yield cost-effective interventions.) 


\subsection{Social Value and Fairness to Research Subjects}

Finally, research involves exposing subjects to risk and harm, which requires countervailing benefits. Even at the stage of preclinical research on animals, ethical guidelines require that the research have social value (Prentice et al. 1992); likewise, Emanuel, Grady, and Wendler propose that research on human subjects must have social value to be ethical (Emanuel et al. 2000). Some propose that research must not only have social value but also be "responsive" or provide "reasonable availability" - that subjects must have a reasonable prospect of benefiting from the intervention being researched (London 2008).

Cost-effectiveness can help contribute to social value, responsiveness, and reasonable availability. For instance, the expected cost-effectiveness of an HPV vaccine regimen can contribute to its social value at the research stage (Lindsey et al. 2013), and the cost-effectiveness of a hemophilia treatment can establish its reasonable availability to participants (Dimichele 2008). Costly research on gene therapy with little evidence of benefit may lack social value (King 2003). Indeed, if we accept a reasonable availability or responsiveness requirement, then human subjects research on interventions that subject populations will never receive because later-stage gatekeepers (such as physicians, approval bodies, or insurers) will not provide them on cost-effectiveness grounds is unethical.

Despite the above arguments, there have been few proposals to incorporate cost-effectiveness standards into research ethics. One exception is Christine Grady and Tito Fojo's recent criticism of cancer treatments that provide small benefits at very high cost, which included a proposal that research be limited on costeffectiveness grounds (Fojo and Grady 2009):

\footnotetext{
Research studies that are powered to detect a survival advantage of 2 months or less should only test interventions that can be marketed at a cost of less than $\$ 20000$ for a course of treatment, which is a monetary value consistent with the cost of one quality adjusted life year in patients treated with artificial renal dialysis (\$129 090). Similarly, a study designed to detect a 4-month advantage can test a therapy that will cost up to $\$ 30000$ per patient.
}

Although Grady and Fojo's proposal generated a great deal of discussion, very little of the discussion focused specifically on their proposed limitation on research. Yet the arguments discussed above give several reasons in support of such a limitation. In the next section, I consider some objections to the consideration of cost-effectiveness in research.

\section{Objections to Considering Cost-Effectiveness at the Research Stage}

\subsection{The Unpredictability of Effectiveness}

One major objection to the use of cost-effectiveness considerations in research involves the difficulty of predicting, at the clinical trial stage, the effectiveness of the intervention being researched. Assessing cost-effectiveness requires an accu- 
rate measure of effectiveness. Two critics of Grady and Fojo's proposal identified this point (Cohen and Looney 2010):

Determining the drug's clinical value is not something that can or should be decided before
a drug's approval, in part because this is what markets do after approval but also because of
the considerable uncertainty associated with a drug's real-world effectiveness.

However, even if effectiveness cannot be as precisely predicted at the research stage as at later stages, there are ways of assessing effectiveness at the trial stage. First, as Grady and Fojo point out, we can use the research study's power as an outer bound on effectiveness: if a study is powered to detect a two-month survival difference, then the study cannot show the intervention to be any more effective than achieving a two-month increment in survival. Second, trial designs have been devised that combine cost-effectiveness predictions with determinations of clinical efficacy (Briggs 2000; Drummond and Stoddart 1984).

\subsection{The Unpredictability of Cost}

The other dimension of cost-effectiveness measures - cost-is also challenging to predict at the clinical trial stage. Cohen and Looney likewise therefore argue that "[i]t is inappropriate for pharmaceutical sponsors to impose de facto price controls on themselves before a drug's approval" (Cohen and Looney 2010). While an intervention's clinical effectiveness is largely determined by human biology, its cost is limited only by human choice. The interventions Grady and Fojo claim we should not research, like cetuximab, could become highly cost-effective if their price was lowered dramatically.

The measurement of drug costs in cost-effectiveness analysis is controversial. The economic ideal is to compare the opportunity cost of the intervention to its benefits (Garrison et al. 2010). However, the market price of a medical intervention does not invariably reflect its opportunity cost. For instance, some payments to providers reflect the effect of patent rents (Palmer and Raftery 1999) or market distortions (Neumann 2009). Estimating costs is particularly difficult at the research stage because so little information is available.

Notwithstanding these difficulties, some cases exist where opportunity costs are easily identifiable even at the research stage, because at least one resource in question is absolutely and immediately scarce. Multiple-organ transplants, for instance, arguably constitute a cost-ineffective use of a scarce resource: they use up multiple organs to save one life when those organs could have saved two or three (Menzel 1994). As such, if we accept the argument against providing multipleorgan transplants, we should also accept a parallel argument against researching such transplants. Likewise, some argued that pharmaceutical companies acted inappropriately in promoting the use of antibiotics to treat less severe conditions when such use would produce resistance that jeopardizes public health (Kessel- 
heim and Outterson 2010). If this is true, research on the efficacy of antibiotics in treating less severe conditions would also be unethical.

The more difficult questions involve whether and how we should evaluate the costs of an intervention at the research stage where absolute scarcity does not exist. This involves predicting the various costs of the intervention, such as the time it will take health professionals to administer it, the wages and profits that will need to be paid to those who develop and provide it, and the cost of raw materials and technical equipment that will be used in developing and administering it. While some of these predictions are technically challenging, empirical and conceptual work on priority setting in research shows promise in helping predict and weigh many of the above costs (Bojke et al. 2007; Fleurence and Torgerson 2004; Torgerson 2002; Rudan 2012).

An important issue in prediction is that some costs - in particular wages and profits - arise from discretionary choices. Pharmaceutical companies could choose to accept lower profits than they do (Schüklenk 2002) or physicians lower incomes (Curzer 1992; Menzel 1985). In particular-as Grady and Fojo suggesttrial sponsors could be required to accept a "cost ceiling" that guarantees that a proposed intervention will be made available at a specified price before research is allowed to proceed. Such a cost ceiling would be analogous to post-trial access requirements that have been imposed in developing-country trials (Grady 2005). If manufacturers refuse to accept a cost ceiling, this undermines their complaint that their research is being unjustly limited on cost-effectiveness grounds, since their demands are what prevent the interventions from being cost-effective. Manufacturers who demand high prices and then complain about limits would be analogous to kidnappers who complain about the hard-heartedness of government refusals to ransom kidnapped individuals (G. Cohen 2010).

Some might worry that forcing manufacturers to direct research toward costeffective interventions will lead to insufficient research into useful medical interventions. However, current trends suggest an excess of research into costly interventions with marginal benefit and a deficit of research on cost-effective interventions (Yamey 2002), so encouraging manufacturers to align their research efforts with cost-effective goals seems warranted.

\subsection{Equity Concerns about Cost-Effectiveness Analysis}

Some have worried that cost-effectiveness analysis is insensitive to concerns about justice and interpersonal equity (Brock 2004); others have gone so far as to entirely reject its use on those grounds (Harris 2005). While cost-effectiveness analysis has flaws, they cannot justify adopting an approach to research, or to any other stage of the process, that entirely ignores cost-effectiveness considerations (Mortimer and Peacock 2012). Rather, cost-effectiveness analysis can and should be improved to take equity values into account (Menzel 1999). 
Likewise, some argue that before imposing limits on interventions that are not cost-effective, we must first address wasteful spending elsewhere, such as in national defense (Angell 1985; Daniels 1986; Schrecker 2013). However, while wasteful defense spending may mitigate the culpability of medical researchers who pursue research on cost-ineffective interventions for the resulting avoidable morbidity and mortality, it does not eliminate their culpability, just as criminals' culpability does not eliminate crime victims' responsibility to avoid injuring innocent bystanders in self-defense (Hurka 2005; McMahan 2011). Indeed, as Harry Frankfurt has argued, two actors can both be fully responsible for an outcome even when neither of their acts alone would have been sufficient to produce the outcome (Frankfurt 1982).

\subsection{Freedom of Intellectual Inquiry}

A final objection is that research is a form of intellectual inquiry, and that requiring researchers to consider cost-effectiveness will stifle free inquiry. While this objection has force in the context of basic science research, it has much less force where human-subject research is concerned. Conducting human-subject research is a privilege that comes with conditions and outside oversight, not a purely private matter between investigator and subject (Dresser 2012). The use of human subjects in research-even with informed consent-requires that the research have social value (Emanuel et al. 2000; Joffe and Miller 2008).

\section{Who Should Ensure that Research Promotes the Development of Cost-Effective Interventions?}

If we accept the ethical legitimacy of incorporating cost-effectiveness considerations at the research stage, we face the challenging question of how costeffectiveness limitations on research should be implemented. Grady and Fojo, for example, do not say who should decide not to pursue clinical trials on interventions that are not cost-effective.

\subsection{Research Ethics Committees}

Research ethics committees, such as institutional review boards (IRBs), could employ cost-effectiveness judgments as part of their evaluation of whether the research in question will have social value. For instance, Berg et al. suggest that it might be appropriate to deny approval for research into enhancement technologies if such technologies prove to lack cost-effectiveness (Berg et al. 2009). Because research ethics committees already have enforcement power and technical expertise, and already review for scientific validity, they seem a natural gatekeeper for ensuring that research has social value (London et al. 2013). However, assessing 
social value arguably lies outside the core expertise of ethics review committees (Rid and Wendler 2010), and many research ethics committees are already overloaded.

Some may argue that an IRB that refuses to approve research on the basis that the interventions produced will not be cost-effective engages in an assessment of the "possible long-range effects of applying knowledge gained in the research," which United States law bars IRBs from engaging in (Mano et al. 2006). However, the legislative intent of this provision was to prevent IRBs from stifling research on controversial topics, such as correlations between race or gender and cognitive ability or criminality (London et al. 2013; Mehlman and Berg 2008). Assessments of cost-effectiveness focus on the importance of the knowledge the research will provide, which IRBs are permitted to assess, rather than the social popularity of the research, which IRBs must not consider.

Finally, the alignment between libertarian objections to IRB review and libertarian objections to regulation of health care by organizations like the FDA (Epstein 2007) suggests that the same political backlash that has prevented the use of cost-effectiveness analysis at other stages (Neumann and Weinstein 2010) may also hamper IRBs in integrating cost-effectiveness norms into research ethics. IRBs attempting to limit human subjects research on cost-effectiveness grounds may be accused of "mission creep" and censorship, as they have been in other contexts (Hyman 2007). IRBs' remarkable insulation from political intervention (Zywicki 2007), however, suggests that they may well succeed where other, more elegant institutional homes for the promulgation of cost-effectiveness norms have not.

\subsection{Research Advisory Committees}

Given IRBs' local focus and their limited expertise and legal authority, several authors have proposed that research advisory committees (RACs) or other central bodies investigate the social implications of research in specific areas, such as behavioral genetics, harm reduction, human enhancement, stem cell research, and post-trial access to interventions (Baylis and Scott Robert 2006; Fleischman et al. 2011; Mano et al. 2006). Research on recombinant DNA technologies is currently overseen by an RAC (King 2002).

Would an RAC be an appropriate body to integrate concerns about the costeffectiveness of interventions into research ethics? Nancy King recommends that RACs be used where "overarching umbrella review and field-wide guidance is needed and useful; cross-study analysis of research data for a field is both possible and desirable; and public access and education are desired" (King 2002). Several of King's considerations - in particular, the need for field-wide guidance and cross-study analysis - do seem applicable to cost-effectiveness. However, costeffectiveness considerations are relevant to every clinical trial, while existing and proposed RACs focus on a particular area of research, such as human enhancement or gene transfer. As such, requiring all proposals to pass through RAC re- 
view might be unworkably broad; however, a RAC playing a more advisory role might be able to collect valuable data on the cost-effectiveness of interventions under research that might in turn inform other actors involved in research decision making. A RAC with enforcement power might also be appropriate for areas of research where cost-effectiveness is uniquely problematic, as Grady and Fojo suggest is true in certain sectors of cancer research.

\subsection{Sponsors}

Another possibility is that trial sponsors should employ cost-effectiveness judgments when deciding whether or not to fund a given clinical trial. To the extent that trials are privately sponsored, sponsors' interest in producing profitable drugs may seem to militate against this option. However, if cost-effectiveness considerations are relevant at downstream stages, such as formulary inclusion, manufacturers may have an economic interest in ensuring that the interventions they research are likely to be adopted in the regulated marketplace. Furthermore, sponsors conducting human subjects research may have ethical obligations other than the maximization of profit, which may include obligations to ensure that the research they sponsor is socially valuable (Shah 2013; Spinello 1992).

\subsection{Investigators}

A fourth possibility is that investigators' codes of ethics should prohibit work on trials that produce interventions that are not cost effective. The possibility of establishing codes of ethics for investigators or revisiting existing codes of ethics has occasionally been discussed as an alternative to IRB review, or as a complement to such review (Shah 2013). A recent boycott of Abbott Laboratories' clinical trials motivated by the high costs of Abbott's HIV drugs seems to reflect some physicians' ethical concern that clinical trials are not leading to the production of cost-effective interventions (Dixon and Richwine 2004).

However, as Shah notes, investigators' ethical obligations-like sponsors' obligations-are under-discussed in the literature (Shah 2013). An investigators' code of ethics that alerts them to the ethical importance of cost-effectiveness, as some codes of ethics do for physicians (Emanuel 2012b), could help ensure that research promotes the development of cost-effective interventions. For instance, Franklin Miller and Steven Joffe's proposed code of ethics for researchers, which regards "promoting socially valuable knowledge about health, disease, and treatment" (emphasis added) as the central aim of human-subject research (Joffe and Miller 2008), justifies researchers' attention to cost-effectiveness to the extent that interventions that are not cost-effective are not socially valuable. Likewise, some scientific codes of ethics emphasize that scientific research must "enhance the public interest or well-being" or otherwise serve the public interest (Resnik and Shamoo 2005). 


\subsection{Research Subjects}

Finally, prospective subjects could refuse to participate in trials that will not produce cost-effective interventions. For instance, breast cancer advocates have advised prospective subjects to "boycott clinical trials by companies that won't agree to price controls, and which maintain secrecy about their true R\&D costs" (Batt 2000). Likewise, a recent initiative in the United Kingdom has exhorted research subjects not to participate in clinical trials that fail to guarantee that their results will be made public (Kmietowicz 2013; Limb 2013). Such initiatives might be made easier by proposals that trial participants be told about the likely future costs of the intervention under study (Barnbaum 2011).

Efforts by research subjects to promote cost-effectiveness face many of the same problems that generally plague workers and consumers attempting to organize (Lynch 2013). For instance, manufacturers can simply pay subjects enough to overcome their objections. Boycotts may end up obstructing research into interventions that are in fact cost-effective, because subjects are unlikely to have access to the most detailed information about future costs or effectiveness. And existing boycott proposals, though congruent with cost-effectiveness, do not take cost-effectiveness as their chief object. Nonetheless, especially if other actors at the research stage are unable or unwilling to assist in implementing costeffectiveness norms, advocacy and collective action by subjects could play an important role in discouraging the production of interventions that are not costeffective.

\section{Conclusion}

This article has presented and evaluated the arguments for and against using research ethics to encourage the production of cost-effective interventions. At this point, I can offer a tempered endorsement of doing so. Promoting the production of cost-effective interventions at the research stage will not, on its own, achieve the long-sought goal of cost control in medicine. Nor would it be wise to scale back cost control efforts at other stages and use research restrictions as the main gatekeeper. The research enterprise is not well suited to be the primary evaluator of cost-effectiveness or primary enforcer of cost-effectiveness norms.

Nonetheless, research can help to share the burden of making cost-effectiveness judgments rather than leaving such judgments to downstream actors such as the FDA, insurers, hospitals, physicians, or patients. Others have argued that physicians must be among the actors empowered to consider cost-effectiveness, because relying solely on approval bodies to contain costs will be undermined by physicians' lack of commitment to cost-effectiveness (Ubel and Arnold 1995). Similarly, if researchers are not committed to cost-effectiveness, they may gener- 
ate a flood of cost-ineffective interventions that overwhelms downstream actors (Rettig 1994). In contrast, judicious adoption of cost-effectiveness norms at the research stage enlists research as part of an "all hands on deck" approach that empowers actors at every level of the scientific and regulatory process to promote the use of cost-effective interventions (Emanuel and Steinmetz 2013). Existing attempts to limit health care costs have not succeeded in stemming their rise. Promoting cost-effective interventions at the research stage could represent an important part of an experimental, multi-level approach-like that adopted in the United States under the Affordable Care Act (Orszag and Emanuel 2010) - to reining in the expanding cost of medical care. ${ }^{1}$

\section{Bibliography}

Angell, M. (1985). Cost containment and the physician. JAMA: The Journal of the American Medical Association, 254(9), 1203-1207.

Barnbaum, D. (2011). You Get What Someone Else Will Pay For. Theoretical \& Applied Ethics 1 (2), 28-31.

Batt S. (2000) The new genetic therapies: the case of Herceptin for breast cancer. In: Miller F, Weir L, Mykitiuk R, Lee P, Sherwin S, Tudiver S, editors. The gender of genetic futures: the Canadian biotechnology strategy, women and health; 2000 Feb 11-12; Toronto. Toronto: National Network on Environments and Women's Health Working Paper Series; 2000. p. 9-17.

Baylis, F., \& Scott Robert, J. (2006). Human embryonic stem cell research: An argument for national research review. Accountability in Research, 13(3), 207 224

Berg, J. W., Mehlman, M. J., Rubin, D. B., \& Kodish, E. (2009). Making All the Children Above Average: Ethical and Regulatory Concerns for Pediatricians in Pediatric Enhancement Research. Clinical Pediatrics, 48(5), 472-480. doi:10.1177/0009922808330457

Black, WC. The CE Plane: a Graphic Representation of Cost-Effectiveness. Medical Decision Making. 1990;10(3):212-4.

Bojke, L., Claxton, K., Sculpher, M. J., \& Palmer, S. (2007). Identifying Research Priorities: The Value of Information Associated with Repeat Screening for Age-Related Macular Degeneration. Medical Decision Making, 28(1), 33-43. doi:10.1177/0272989X07309638

Briggs, A. (2000). Economic evaluation and clinical trials: size matters. $B M J$ (Clinical research ed.), 321(7273), 1362-1363.

\footnotetext{
${ }^{1}$ I am grateful to John Phillips for his helpful written comments on an earlier draft, and to attendees at the Conference on Current Challenges in Preclinical, Clinical, and Public Health Ethics, Hannover Medical School, 2013 for their comments.
} 
Buchanan DR, Miller FG. Justice and Fairness in the Kennedy Krieger Institute Lead Paint Study: the Ethics of Public Health Research on Less Expensive, Less Effective Interventions. Am J Public Health. 2006;96(5):781-7.

Cohen, G. A. (2010). Rescuing justice and equality.

Cohen J, Looney W. Re: How Much Is Life Worth: Cetuximab, Non-Small Cell Lung Cancer, and the \$440 Billion Question. JNCI. 2010;102(15):1207-7.

Curzer, H. J. (1992). Do physicians make too much money? Theoretical medicine, $13(1), 45-65$.

Daniels, N. (1986). Why saying no to patients in the United States is so hard. New England Journal of Medicine, 314(21), 1380-1383

Denny CC, Emanuel EJ. US Health Aid Beyond PEPFAR: the Mother \& Child Campaign. JAMA. 2008;300(17):2048.

Dimichele DM. Ethical Considerations in Clinical Investigation: Exploring Relevance in Haemophilia Research. Haemophilia. 2008;14(s3):122-9.

Dixon, K., \& Richwine, L. (2004, February 10). Doctors Call for Abbott Boycott on AIDS Price Hike. Reuters.

Dowie J. Why Cost-Effectiveness Should Trump(Clinical) Effectiveness: the Ethical Economics of the South West Quadrant. Health Econ. 2004;13(5):453-9.

Dresser R. Alive and Well: the Research Imperative. J Law Med Ethics. 2012;40(4):915-21.

Drummond, M. F., \& Stoddart, G. L. (1984). Economic analysis and clinical trials. Controlled clinical trials, 5(2), 115-128.

Emanuel, E. J., \& Steinmetz, A. (2013). Will Physicians Lead on Controlling Health Care Costs? Editorial. JAMA. doi:10.1001/jama.2013.8278

Emanuel EJ. PEPFAR and Maximizing the Effects of Global Health Assistance. JAMA. 2012a;307(19):2097-100.

Emanuel EJ. Review of the American College of Physicians Ethics Manual. Ann Intern Med. 2012b;156(1):56-7.

Emanuel EJ, Fuchs VR. The Perfect Storm of Overutilization. JAMA. 2008;299(23):2789-91

Emanuel EJ, Wendler D, Grady C. What Makes Clinical Research Ethical? JAMA. 2000;283(20):2701-11.

Epstein, R. A. (2007) The Erosion of Individual Autonomy in Medical Decisionmaking: Of the FDA and IRBs, Geo. LJ, 96, 559

Fleurence, R. L., \& Torgerson, D. J. (2004). Setting priorities for research. Health policy, 69(1), 1-10. doi:10.1016/j.healthpol.2003.11.002

Fleischman, A., Levine, C., Eckenwiler, L., Grady, C., Hammerschmidt, D. E., \& Sugarman, J. (2011). Dealing With the Long-Term Social Implications of Research. The American Journal of Bioethics, 11(5), 5-9. doi:10.1080/15265161.2011.560337

Fojo T, Grady C. How Much Is Life Worth: Cetuximab, Non-Small Cell Lung Cancer, and the \$440 Billion Question. JNCI. 2009;101(15):1044-8.

Frank E, Rush AJ, Blehar M, Essock S, Hargreaves W, Hogan M, Jarrett R, Johnson RL, Katon WJ, Lavori P. Skating to Where the Puck Is Going to Be: a Plan 
for Clinical Trials and Translation Research in Mood Disorders. Biol Psychiat. 2002;52(6):631-54.

Frankfurt, H. G. (1971). Freedom of the Will and the Concept of a Person. The Journal of Philosophy, 68(1), 5-20.

Garber AM. Can Technology Assessment Control Health Spending? Health Aff. 1994;13(3):115-26.

Garrison, L. P., Jr., Mansley, E. C., Abbott, T. A., III, Bresnahan, B. W., Hay, J. W., \& Smeeding, J. (2010). Good Research Practices for Measuring Drug Costs in Cost-Effectiveness Analyses: A Societal Perspective: The ISPOR Drug Cost Task Force Report-Part II. Value in Health, 13(1), 8-13. doi:10.1111/j.1524-4733.2009.00660.x

Girardi E, Angeletti C. Much Cheaper, Almost as Good Treatment: a Possible Approach to Guarantee Sustainability of HIV Care? HAART, HIV correlated pathologies and other infections. 2013(18):175-8.

Grabowski H. The Role of Cost-Effectiveness Analysis in Managed-Care Decisions. Pharmacoeconomics. 1998;14(1)Suppl:15-24.

Grady, C. (2005). The challenge of assuring continued post-trial access to beneficial treatment. Yale journal of health policy, law, and ethics, 5(1), 425-435.

Harris, J. (2005). It's not NICE to discriminate. Journal of Medical Ethics, 31(7), 373-375. doi:10.1136/jme.2005.01290.

Hurka, T. (2005). Proportionality in the Morality of War. Philosophy \& Public Affairs, 33(1), 34-66.

Hyman, D. A. (2007). Institutional review boards: is this the least worst we can do? Northwestern University Law Review, 101, 749.

Joffe, S., \& Miller, F. G. (2008). Bench to bedside: mapping the moral terrain of clinical research. The Hastings Center Report, 38(2), 30-42

Kesselheim AS, Outterson K. Fighting Antibiotic Resistance: Marrying New Financial Incentives to Meeting Public Health Goals. Health Aff. 2010;29(9):1689-96.

King, N. M. P. (2002). RAC oversight of gene transfer research: a model worth extending? The Journal of Law, Medicine \& Ethics, 30(3), 381-389.

King NMP. Accident \& Desire. Inadvertent Germline Effects in Clinical Research. Hastings Cent Rep. 2003;33(2):23-30.

Kmietowicz, Z. (2013). Patients are urged to boycott trials that do not guarantee publication. BMJ (Clinical research ed.), 346(jan08 13), f106-f106. doi:10.1136/bmj.f106

Lederle FA, Rogers EM. Lowering the Cost of Lowering the Cholesterol: a Formulary Policy for Lovastatin. J Gen Intern Med. 1990;5(6):459-63.

Lie RK. Research Ethics and Evidence Based Medicine. J Med Ethics. 2004;30(2):122-5.

Limb, M. (2013). NICE joins campaign for full disclosure of clinical trial data. BMJ: British Medical Journal, 346. 
Lindsey JC, Shah SK, Siberry GK, Jean-Philippe P, Levin MJ. Ethical Tradeoffs in Trial Design: Case Study of an HPV Vaccine Trial in HIV-Infected Adolescent Girls in Lower Income Settings. Dev World Bioeth. 2013;13(2):95-104.

London, A. J. (2008). Responsiveness to host community health needs. In Ezekiel J. Emanuel, Robert Crouch, Christine Grady, Reidar Lie, Franklin Miller, and David Wendler eds., The Oxford Textbook of Clinical Research Ethics (New York: Oxford University Press, 2008): 737-46.

London, A. J., Kimmelman, J., \& Emborg, M. E. (2013). Beyond access vs. protection in trials of innovative therapies. Science, 328(5980), 829-830.

Lynch, H. (2013). Protecting Human Research Subjects as Human Research Workers. The Future of Human Subjects Research Regulation, I. Glenn Cohen and Holly Fernandez Lynch, eds., MIT Press (Spring 2014)(Forthcoming).

Mano, M. S., Rosa, D. D., \& Lago, L. D. (2006). Multinational clinical trials in oncology and post-trial benefits for host countries: where do we stand? European Journal of Cancer, 42(16), 2675-2677. doi:10.1016/j.ejca.2006.02.028

McMahan, J. (2011). Proportionality in the Afghanistan War. Ethics \& International Affairs, 25(2), 143-154

Mehlman, M. J., \& Berg, J. W. (2008). Human Subjects Protections in Biomedical Enhancement Research: Assessing Risk and Benefit and Obtaining Informed Consent. The Journal of Law, Medicine \& Ethics, 36(3), 546-549.

Menzel, P. T. (1985). Medical Costs, Moral Choices.

Menzel PT. Rescuing Lives: Can't We Count? Hastings Cent Rep. 1994;24(1):223.

Menzel, P., Gold, M. R., Nord, E., Pinto-Prades, J. L., Richardson, J., \& Ubel, P. (1999). Toward a broader view of values in cost-effectiveness analysis of health. The Hastings Center Report, 29(3), 7-15.

Neumann, P. J. (2009). Costing and perspective in published cost-effectiveness analysis. Medical care, 47(7_Supplement_1), S28-S32.

Neumann, P. J., \& Weinstein, M. C. (2010). Legislating against use of costeffectiveness information. The New England journal of medicine, 363(16), 1495-1497. doi:10.1056/NEJMp1007168

Ord T. The Moral Imperative Towards Cost-Effectiveness in Global Health. Center for Global Development. 2013. http://www.cgdev.org/publication/moralimperative-toward-cost-effectiveness-global-health. Accessed 13 Jan 2015.

Orszag PR, Ellis P. Addressing Rising Health Care Costs-a View From the Congressional Budget Office. New Engl J Med. 2007;357(19):1885-7.

Orszag, P. R., \& Emanuel, E. J. (2010). Health care reform and cost control. New England Journal of Medicine, 363(7), 601-603

Palmer, S., \& Raftery, J. (1999). Economic Notes: opportunity cost. BMJ (Clinical research ed.), 318(7197), 1551-1552.

Paltiel AD, Pollack HA. Price, Performance, and the FDA Approval Process: the Example of Home HIV Testing. Med Decis Making. 2010;30(2):217-23. 
Mortimer D, Peacock S. Social Welfare and the Affordable Care Act: Is It Ever Optimal to Set Aside Comparative Cost? Soc Sci Med. 2012;75(7):1156-62.

Prentice, E. D., Crouse, D. A., \& Mann, M. D. (1992). Scientific merit review: the role of the IACUC. ILAR Journal, 34(1-2), 15-19.

Resnik, D. B., \& Shamoo, A. E. (2005). Bioterrorism and the Responsible Conduct of Biomedical Research. Drug Development Research, 63(3), 121-133. doi:10.1002/ddr.10406

Rettig, R. A. (1994). Medical innovation duels cost containment. Health Affairs, 13(3), 7-27. doi:10.1377/hlthaff.13.3.7

Rid, A., \& Wendler, D. (2010). Risk-benefit assessment in medical research-critical review and open questions. Law, Probability and Risk, 9(3-4), 151177. doi:10.1093/1pr/mgq006

Roughead EE, Gilbert AL, Vitry AI. The Australian Funding Debate on Quadrivalent HPV Vaccine: a Case Study for the National Pharmaceutical Policy. Health Policy. 2008;88(2-3):250-7.

Rudan, I. (2012). Global health research priorities: Mobilizing the developing world. Public Health, 126(3), 237-240. doi:10.1016/j.puhe.2011.12.001

Schrecker, T. (2013). Interrogating scarcity: how to think about "resource-scarce settings." Health Policy and Planning, 28(4), 400-409. doi:10.1093/heapol/czs071

Schüklenk, U., \& Ashcroft, R. E. (2002). Affordable access to essential medication in developing countries: conflicts between ethical and economic imperatives. Journal of Medicine and Philosophy, 27(2), 179-195. doi:10.1076/jmep.27.2.179.2989

Shah, S. K. (2013). Outsourcing ethical obligations: should the revised common rule address the responsibilities of investigators and sponsors?. The Journal of Law, Medicine \& Ethics, 41(2), 397-410.

Spinello, R. A. (1992). Ethics, pricing and the pharmaceutical industry. Journal of Business Ethics, 11(8), 617-626

Thomson S. Schang L, Chernew ME. Value-Based Cost Sharing in the United States and Elsewhere Can Increase Patients' Use of High-Value Goods and Services. Health Aff. 2013;32(4):704-12.

Tobert JA. Case History: Lovastatin and Beyond: the History of the HMG-CoA Reductase Inhibitors. Nat Rev Drug Discov. 2003;2(7):517-26.

Torgerson, D. J., \& Byford, S. (2002). Economic modelling before clinical trials. BMJ (Clinical research ed.), 325(7355), 98.

Ubel, P. A., \& Arnold, R. M. (1995). The unbearable rightness of bedside rationing. Physician duties in a climate of cost containment. Archives of internal medicine, 155(17), 1837-1842.

Weinberger, S. E. (2011). Providing high-value, cost-conscious care: a critical seventh general competency for physicians. Annals of internal medicine, 155(6), 386-388. doi:10.7326/0003-4819-155-6-201109200-00007 
Wendler D, Emanuel EJ, Lie RK. The Standard of Care Debate: Can Research in Developing Countries Be Both Ethical and Responsive to Those Countries' Health Needs? Am J Public Health. 2004:94(6):923-8.

Wilensky GR. Developing a Center for Comparative Effectiveness Information. Health Aff. 2006;25(6):w572-85.

Woods S, Taylor K. Ethical and Governance Challenges in Human Fetal Tissue Research. Clin Ethics. 2008;3(1):14-9.

Yamey, G. (2002). The world's most neglected diseases: Ignored by the pharmaceutical industry and by public-private partnerships. BMJ: British Medical Journal, 325(7357), 176.

Zywicki, T. J. (2007). Institutional review boards as academic bureaucracies: An economic and experiential analysis. Northwestern University Law Review, 101,861 . 